\title{
Bronchiolitis in adult: A review
}

\author{
Alcibey Alvarado ${ }^{1 *}$ and Isabel Arce ${ }^{2}$ \\ ${ }^{1}$ Internal Medicine and Neumology, Clínica de Diagnóstico Médico, San José, Costa Rica \\ ${ }^{2}$ Medicine and General Surgery, Medicine School, University of Costa Rica. San José, Costa Rica
}

\begin{abstract}
Few diseases have a greater effect on the health of young children than viral respiratory illness of lower tract. This does not happen in adults, possibly due to the different states of activation and expression of the innate immune response and acquired immune responses in these two age groups. Bronchiolitis is a general term used to describe non-specific inflammatory injury that primarily affects the small airways and generally limits the extent to interstice. In the adult clinic, conventional and high-resolution radiology and respiratory functional studies are suggestive of the diagnosis but the etiology usually requires tissue. For this reason, in this work, although there are clinical and radiological classifications, we will use the histologic classification. The goal is a simple, concise and updated monograph issue discussing the different types of adult bronchiolitis, pathophysiology, diagnosis and current therapeutic options.
\end{abstract}

\section{Introduction}

Bronchiolitis is a disease of the small airways, which are defined as airways with less than $2 \mathrm{~mm}$ in diameter and no cartilage [1]. Membranous bronchioles have full fibromuscular wall but this wall is very thin [2]. Bronchioles derived from the tertiary bronchus and form a transition area between the major airways and lung parenchyma and fundamentally have a centrilobular location. For its abundant structure (occupy an important area of the airway), its respiratory mechanics (without cartilage and small diameter), the transport of gases to and from the alveoli and their defense mechanism, are particularly vulnerable to infectious, inhaled, vascular, pharmacological and immunological injury [3]. The primary symptoms of bronchiolitis are coughing and dyspnea and during the respiratory auscultation crackles and/or wheezing can be perceived. Respiratory function tests revealed a nonreversible obstructive defect, hyperinflation and generally decreased diffusion (DLCO). Some jobs just used as functional obstructive criteria the reduced FEV1, FVC and FEV1/FVC [2]. There is subtle evidence of early detection of small airway dysfunction such as closing volume, closing capacity, dynamic compliance, the isoflow-volume and forced oscillation technique (FOT) $[4,5]$. FOT is a convenient tool for measuring respiratory mechanics (resistance and reactance) by applying external oscillatory pressure during tidal breathing [6]. The detail in these tests is generally used in research and does not always have work routine diagnosis of respiratory diseases, particularly in third world countries. The flow-volume curve has greater availability and forced expiratory flow between $25 \%-75 \%$ of FVC (FEF25\%-75\% and FEF50\%) is used more broadly as sensitive measure of function of small airways. These tests allow early detection of small airways dysfunction, they are very sensitive, unspecific and less reproducible $[7,8]$. FEV1, that predominantly identifies airflow obstruction in airways with diameter greater than $2 \mathrm{~mm}$, can be reduced but in more advanced stages. When the process is very extensive and diffuse, with severe airflow obstruction can add a mild restriction [9].

The result of chest radiography may be normal. The high-resolution CAT (HRCT) is the imaging study of choice, and the characteristic findings include areas trapping gas, thickening of the bronchial wall and centrilobular nodules. Whether the CAT is contrasted (as practiced in interstitial lung disease protocol, with inspiratory and expiratory phases and prone decubitus) or without contrast, the trapping of air is expressed when there is no significant difference in attenuation coefficient (Hounsfield units) between the inspiratory and expiratory image. This trap occurs by bronchiolar obstruction [10]. The air trap can be diffuse or mosaic perfusion (geographical areas with variable attenuation of patchy distribution) that are most obvious in the expiratory phase [2]. The bronchial wall thickening occurs by cellular infiltration and / or fibrosis, and by the extension of both elements to peribronchial tissue. Centrilobular nodules are consistent with the anatomical localization of the bronchioles [11]. The nodule size is variable. In some types of bronchiolitis just $2 \mathrm{~mm}$ in diameter and thus they are not visible on conventional radiography or are invisible by the gas entrapment. While there are other suggestive radiological patterns of some particular forms of bronchiolitis, these three findings are common to most of them.

\section{Acute bronchiolitis}

Approximately $20 \%$ of the annual birth cohort, require outpatient medical attention during the first year of life because of illness caused by RSV [12]. Estimated nationwide hospital charges for care related to bronchiolitis in children younger than 2 years of age exceeded $\$ 1.7$ billion in 2009, in USA [13]. Globally, in 2005, RSV alone was estimated to cause 66.000 to 199.000 deaths among children younger than 5 years, with a disproportionate number of these deaths occurring in resource-limited countries $[14,15]$. The picture is not so clear in adults with acute bronchiolitis. In adults, it has been reported in patients with Mycoplasma pneumoniae, RSV, measles, influenza, pertussis, parainfluenza, and adenovirus [16]. The clinical presentation is poorly

Correspondence to: Alcibey Alvarado, 1Internal Medicine and Neumology, Clínica de Diagnóstico Médico, San José, Costa Rica, Tel: 50622237134; 50622566439; 50688783325; 50687351858; Fax: 50622216754; E-mail: alcialvagonza@yahoo.com.mx

Key words: small airways, inflammation, bronchiolitis

Received: January 14, 2017; Accepted: February 03, 2017; Published: February 06,2017 
defined unlike children. Often, a disease of the upper respiratory tract precedes the onset of symptoms of lower respiratory tract of cough, exertional dyspnea, fever, tachypnea, and wheezing. Generally, if no risk factors, is self-limited [1].

RSV is now recognized as a significant problem in certain populations of adults, including the elderly patient, people with cardiopulmonary disease, and immunocompromised host. The impact of RSV in older adult may be similar to influenza not pandemic. In addition, RSV causes $2-5 \%$ of community-acquired pneumonia in adults [17]. In long-term care facilities RSV is predictable cause of respiratory disease, infecting $5-10 \%$ of residents per year, with rates of pneumonia $10-20 \%$ and death in $2-5 \%$, but the percentage of these patients with bronchiolitis is not known. In one series, CT showed thickening of bronchial walls, centrilobular nodules and / or pattern of "tree-in-bud" [18]. Occasionally, this acute syndrome has been reported to progress to bronchiolitis obliterans. They have recently reported other viruses such as EV D68 (an enterovirus) causing bronchiolitis in adults, associated with low levels of IgG3 and bronchial hyperreactivity up to 5-7 years after bronchiolitis in infancy associated with polymorphism of TLR4 (Toll-like receptors) and deterioration of lung function in children with polymorphism the TLR7 $[8,19]$.

\section{Proliferative bronchiolitis}

It is a distinctive histopathological pattern in which characteristic intra-luminal fibrotic buds, called Masson bodies, extend beyond alveolar ducts to alveoli. When proliferative bronchiolitis is associated with extension of inflammatory cells into the more distal pulmonary parenchyma, the process is called organizing pneumonia. It is not uncommon finding foamy macrophages in the alveolar spaces [20]. This histopathological finding is associated with many pulmonary disorders. Proliferative bronchiolitis is particularly extensive or prominent in patients with cryptogenic organizing pneumonia (COP), previously called idiopathic bronchiolitis obliterans organizing pneumonia (BOOP). COP is one of seven idiopathic interstitial pneumonias and results from injury to the alveolar epithelium, although the bronchioles are usually committed due to its close proximity [21]. It can also be found as a minor finding in other interstitial diseases, such as chronic eosinophilic pneumonia, hypersensitivity pneumonitis, idiopathic pulmonary fibrosis and nonspecific interstitial pneumonia. It may also occur by exposure to nitrogen dioxide. HCRT show patchy airspace consolidation, "ground-glass" opacity and small nodular opacities in the periphery and in lower lung areas. When the proliferative bronchiolitis is the predominant histological finding, the next step is to determine whether it is cryptogenic organizing pneumonia or secondary. This bronchiolitis typically responds to glucocorticoids; the specific regimen depends on the clinical changes and the underlying cause [22].

\section{Follicular bronchiolitis}

This bronchiolitis (FB) is a polyclonal hyperplasia of bronchiolar associated lymphoid tissue (BALT) produced by antigen stimulation, with reactive germinal centers distributed along the bronchioles and bronchi to a lesser extent, and associated with low interstitial disease. Well-structured lymphoid follicles are located between the bronchioles and pulmonary arteries and hyperplasia following compress the light of the bronchioles causing obstruction or complete obliteration [23]. This entity is part of the "lymphoproliferative pulmonary diseases" (LPDs) and is associated with connective tissue diseases (rheumatoid arthritis, Sjögren's syndrome), interstitial lung diseases (ILDs), disorders of mixed collagen-vascular, obstructive diseases of airways and states immunodeficiency including HIV and common variable immunodeficiency (CVID) (secondary FB) $[10,24]$. When there is no such association it's classified as primary FB. LPDs, in turn, include three groups of pathologies: 1) reactive/non-neoplastic lymphoid lesions that are subdivided based on the pattern of lung involvement in lymphoid nodular hyperplasia (LNH) (focal commitment); FB (peribronchiolar commitment); lymphoid interstitial pneumonia (LIP) (diffuse involvement with lung cysts) 2) lymphoproliferative malignant parenchymal lesions that are subdivided into primary and secondary. Primary ( $0.5 \%$ of all primary lung neoplasms) include lymphomas of extranodal marginal zone of origin MALT (lymphoma MALT), diffuse large B-cell lymphoma (DLBCL) and lymphomatoid granulomatosis (LYG). The second ones include Non-Hodgkin lymphoma (NHL) and Hodgkin lymphoma (HL). [3] immunocompromised host lymphoproliferative disorders, including lymphoma related to acquired immune deficiency syndrome (AIDS) (ARL) and post-transplant lymphoproliferative disorder (PTLD) [25]. Pulmonary function tests in patients with FB are generally nonspecific and may be normal, restrictive, obstructive or mixed pattern of airflow limitation.

CT cardinal changes are the small centrilobular nodules associated, sometimes to peribronchiolar nodules and "ground-glass" areas. One of the most distinctive patterns that have been associated with bronchiolar disease is "tree-in-bud" pattern, representing impaction with secondary bronchiolar exudate material infection or inflammation [26]. The presence of peribronchiolar inflammation and formation of peribronchiolar lymphoid follicles may appear as a "tree-in-bud" on HRCT, because the lymphoid follicles become heavily concentrated in the area adjacent to the bronchioles gap and fade away from the interstitium furthest from the airway. This pattern on HRCT has been described as "cotton-in-bud". The dilated and thick-walled bronchioles give the appearance that pathologically correlates with follicular bronchiolar obstruction [26]. Histological diagnosis requires two fundamental changes: the presence of lymphoid follicles well formed on the walls of the bronchioles and secondary obstruction or complete obliteration of the bronchiolar light. Distribution is mainly in the interlobular septa and low in the alveolar septa, whereas the diffuse involvement of the latter is considered the key feature of the LIP [27]. Yet, many pathologists today describe these two entities as a continuum of reactive, lymphoid lung diseases, where in many cases distinction is arbitrary. FB associated secondary histological changes are organizing pneumonia, obstructive pneumonia, and infiltrates of intraluminal bronchiolar neutrophils [28]. Immunohistochemistry is essential to rule out malignancy. In the absence of primary immunodeficiency states, FB usually reveals positive for CD79a and CD20 on B cells, predominantly within lymphoid peribronchiolar aggregates, and CD3 positive in T cells, predominantly in the alveolar interstice when there is overlap with LIP [29]. Clinicopathological and radiological correlation is essential for differential diagnosis.

In $\mathrm{FB}$, the basic operation is to treat the underlying disease. In patients with CVID, intravenous gamma globulin may reduce the frequency and severity of lung infections. Rituximab and azathioprine combined have recently demonstrated radiographic improvement and lung function in these patients [30]. When FB is associated with interstitial disease, treatment usually involves immunosuppressive therapy. The FB associated with HIV generally improves with the initiation of anti-retroviral therapy [24]. In the idiopathic form, the anecdotal use of steroids has reported improvement in clinical symptoms and radiological abnormalities [31]. However, there are 
no established guidelines for the treatment of primary FB. Macrolides have been used, possibly with symptomatic improvement for its antiinflammatory properties [32]. The prognosis depends on two factors, age at time of disease presentation and background. Patients middleaged and older with primary FB are more favorable prognosis, while under 30 years and immunodeficient background tend to develop more progressive disease with high mortality [33].

\section{Respiratory bronchiolitis}

Respiratory bronchiolitis (RB) is a well-recognized histological lesion found in the lungs of many young smokers, but is usually asymptomatic. It is recognized by the presence of clusters of tanpigmented macrophages in the respiratory bronchioles. These intraluminal macrophages are accompanied by a patchy submucosal and peribronchiolar infiltrate of lymphocytes and histiocytes. Peribronchiolar fibrosis extends in a stellate pattern into contiguous alveolar walls [4]. The inflammatory profile in normal smokers is very similar to that of patients with chronic obstructive pulmonary disease (COPD), but less prominent. The concept that emerges is that there is an amplified response in patients with COPD [34]. The RB may be responsible for subtle functional alterations in young smokers and may precede the development of emphysema in genetically predisposed patients. This becomes very important because the RB can be resolved after stopping smoking and this information could be relevant in the anti-smoking campaigns. When the RB is more severe, symptoms usually translate a greater interstitial involvement and then is called respiratory bronchiolitis-associated interstitial lung disease (RB-ILD). On HRCT, RB-ILD is associated with diffuse or patchy "ground-glass" opacities, fine nodules, and air trapping, predominantly in the upper lobes.

\section{Airway-centered interstitial fibrosis}

Airway-centered interstitial fibrosis (ACIF) is a disease that has been recognized relatively recent and particularly affects women between 40-60 years of age [35]. Also, known as idiopathic bronchiolocentric interstitial pneumonia or chronic bronchiolitis with fibrosis, is a form of bronchiolitis in which the key histopathological finding is a centrilobular and bronchiolocentric inflammatory infiltrate with peribronchiolar fibrosis and an absence of granulomas [36]. Prominent epithelial hyperplasia compromising the adjacent alveolar septa is usually present; squamous metaplasia, goblet cell metaplasia and necrosis have been described. In clinical groups, it was thought to have hypersensitivity pneumonitis (HP) characteristics but not specific antigens were identified. Many patients reported to have been smokers. Others had chronic silent microaspiration, hypersensitivity or toxic reactions, turning it difficult to segregate the contribution of each factor [37]. The clinical picture is of a chronic nonproductive cough, progressing faster than HP, no specific interstitial pneumonia (NSIP) or RB-ILD, the other diagnoses have a similar presentation. The lung function tests can show obstructive or restrictive patterns. HRCT scans of ACIF show a combination of "ground-glass" opacities, traction bronchiectasis, and bronchial wall thickening. This latter finding is characteristic of most advanced peribronchiolar fibrosis [20]. Unlike HP, the percentage of lymphocytes in the bronchoalveolar lavage (BAL) is less than $40 \%$. The diagnosis is based on lung biopsy. The treatment is not known. Some patients improve with inhaled or systemic glucocorticoids, but the disease progresses generally in at least half of the patients reported, although ACIF has better prognosis than idiopathic pulmonary fibrosis [35].

\section{Diffuse aspiration bronchiolitis}

This bronchiolitis is a poorly defined and occult entity. It's found most often in young or middle-aged patients with identifiable risk factors such as gastroesophageal reflux disease (GERD), drug abuse and dysphagia [38]. A retrospective study of 20 patients found that cough, sputum production, dyspnea, and fever in patients with a history of recurrent pneumonia that did not respond to antimicrobial therapy were the most common manifestations [39]. A high index of suspicion is required to make the diagnosis. Chest CT findings are micro-nodules and opacities "tree-in-bud". The management of these patients should focus on the prevention of recurrent aspiration and treatment of GERD.

\section{Diffuse panbronchiolitis}

Diffuse panbronchiolitis (DPB) is a distinct clinicopathologic syndrome that primarily affects Japanese, Korean, Chinese and Thai middle age men and rarely reported outside South-East Asia. It affects the lower and upper respiratory tract, leading to progressive evolution bronchiectasis, recurrent infections and generally sinusitis [9]. Histological injury DPB is focused on the respiratory bronchioles, and consists of a transmural infiltrate of lymphocytes, plasma cells and distinctive lipid-laden "foamy" macrophages, with extension to peribronchiolar tissue. In advanced stages, there's obstruction and constriction of lumen, proliferation of lymphoid follicles and secondary ectasia of terminal bronchioles. The functional pattern is essentially obstructive.

The etiology is unknown, although it appears to be a genetic predisposition. For example, the HLA-B54 is associated with PBD in Japanese while HLA-A11 in Korean [40]. It has been suggested that in any position between HLA-B and HLA-A, a mutation of a suspicious gene susceptible to the disease in a single ancestral chromosome containing HLA-B54 and HLA-A11 occurred. Then it is possible that a series of genetic recombination events around the locus (location on a chromosome) of the disease could have resulted in the association of the disease with HLA-B54 in Japanese and HLA-A11 in Korean. Additionally, the diseases caused by HLA genes identified in the region of susceptibility to PBD have been investigated. One of these, "bare lymphocyte syndrome I" (BLS I) has a number of similarities with PBD, including chronic sinusitis, inflammation and bronchiolar nodules, and $H$. influenzae and Pseudomonas auroginosa in those affected. As the PBD, the BLS I respond to treatment with erythromycin, showing resolution of symptoms. The similarity between the two entities, the result to the same type of treatment, and the fact that the gene responsible for BLS I was causing the PBD, narrows the field for a responsible gene within the PBD area [41]. The radiological image consists of small nodular shadows to $2 \mathrm{~mm}$ in diameter, diffusely scattered in both lungs that can be invisible by hyperinflation of alveoli and the sign of "tree-in-bud" [42]. Effective treatment is based on macrolides such as erythromycin and roxithromycin and for extended time and at low doses, mainly for its immunomodulatory effect [43]. While it is true that the histological diagnosis is desirable, with the appropriate facilities, compatible physiological and radiological changes and the geographical location, lung biopsy is usually unnecessary and a course of macrolides is adequate. The prognosis is good. The survival rate at 10 years of PBD is about $90 \%$. The disease has no known cure.

\section{Obliterants bronchiolitis}

Also, known as obliterative bronchiolitis (OB), it is a syndrome associated with small airways damage caused by a spectrum of exposure 
to drugs, inhalation, or infection and also to transplantation of the lung and hematopoietic cells (HSCT) [16]. The clinical syndrome is typically characterized by dyspnea, non-reversible airflow limitation with bronchodilators, and normal chest $\mathrm{x}$-ray or pulmonary hyperinflation. The pathogenesis is not clear. Injury to the bronchial epithelium seems to initiate the process that may involve the alveoli adjacent to the small pathways. As in many other inflammatory processes in the human economy, repair may result in complete recovery or excessive proliferation of granulation tissue that causes obstruction or obliteration of the bronchiolar lumen (constrictive bronchiolitis) [44].

There is a wide range of agents and diseases that can cause the obliterating event. Inhalation of nitrogen dioxide, nitrogen mustard, ammonia, welding vapors, ash, food flavoring fumes (diacetyl and 2,3-pentanedione), SRV infection, adenovirus, or Mycoplasma pneumoniae, busulfan, gold or penicillamine treatment, and exposure to combustion air wells in the desert in soldiers, have been described as causes [45,46]. Rheumatoid arthritis and other rheumatic diseases can lead to OB [7]. In addition, OB is a respiratory manifestation of graft vs host disease (GVHD) in patients undergoing lung transplantation or HSCT. It occurs in $6 \%$ of allogeneic HSCT and in this group of patient's survival is only $13 \%$ to 5 years [47]. Club cells (originally called Clara cells) promote the regeneration of airway epithelium and may be reduced in number or eliminated as a result of epithelial injury. Certain polymorphisms of genes of the immune system favor this phenomenon which represents a rejection of the allo-graft towards the host and is an expression of GVHD [2]. The condition typically develops within the first 2 years of transplantation, although it can occur several years later.

In patients with lung transplantation there is an added complication of microvascular insufficiency in the small airways of the transplanted lung, which presumably occurs because blood supply to the bronchial arteries is interrupted during transplantation. This could lead to defective repair if subsequent immune or non-immune injury occurs $[48,49]$. Compared with normal lungs, transplanted lungs are more susceptible to allo-immune immunological insult and airway insult, and they have limited resilience. It is therefore not surprising that $O B$ affects longer-term lung transplant survivors, with the likelihood of remaining free from disease $(\mathrm{OB})$ less than $30 \%$ at 10 -year term $[50,51]$. Common immunosuppressive regimens have also been implicated in the pathogenesis of OB. They include calcineurin inhibitors (cyclosporin, tacrolimus and everolimus), inhibitors of purine synthesis (azathioprine or mycophenolate mofetil) and glucocorticoids [52-54]. Treatments for OB after HSCT or lung transplant have several controversial points. First, they are based on small and retrospective series. Second, the studies evaluated responses to treatments in which the primary focus was GVHD and not specifically OB. Third, studies are difficult to interpret because the severity of $\mathrm{OB}$ varied widely among the patients studied. Possibly the OB has different clinical phenotypes, which condition different responses to therapy. Azithromycin has improved lung function in $50 \%$ of patients transplanted with $\mathrm{OB}$ and also survival $[55,56]$. The mechanism of action appears to be a decrease in airway neutrophilia and related cytokine activation [57]. FAM (fluticasone, azithromycin and montelukast) have been used for OB post-transplantation. Lung transplantation in end stage OB in HSCT or in a first lung transplant is an accepted therapy in carefully selected patients [2]. As with other types of bronchiolitis, $\mathrm{OB}$ can be seen in inflammatory bowel disease. Pemphigus vulgaris is a lifethreatening autoimmune disease of the skin and mucous membranes caused by autoimmune IgG against desmoglein 3 (Dsg3), a cell-to-cell adhesion molecule of keratinocytes [58]. Rarely, OB has been reported associated with paraneoplastic pemphigus, sometimes occurring prior to the appearance of the underlying neoplasia. On rare occasions, OB is idiopathic or cryptogenic [59]. OB should be considered in patients presenting with insidious onset of dyspnea and cough, especially when the symptoms and signs do not follow a typical pattern of asthma or COPD or if the patient has a predisposing exposure or condition; for example, symptoms of viral infection, exposure to toxic vapors, history of organ transplantation, or concomitant connective tissue disease. $\mathrm{OB}$ must enter the differential diagnosis of irreversible obstruction to airflow or associated with reduction in the transfer of gases in nonsmokers. Pulmonary function tests may initially be normal or show an obstructive pattern with gas trapping and no reversibility with inhaled bronchodilators [46]. Given the vast number of bronchioles, of which a large number will be narrowed or clogged, a significant loss of function occurs, which explains the occasional restrictive disorder and the reduction of DLCO [60].

In many cases of $\mathrm{OB}$, conventional radiography is normal or shows only thickening of the bronchial wall or hyperinflation (without flattening of diaphragms or hyperlucent areas suggestive of emphysema). HRCT is the technique that best identifies the findings consistent with $\mathrm{OB}$, particularly if images are obtained in inspiration and expiration. Trapping of expiratory gas (diffuse or mosaic), thickening of bronchial walls (linear opacities that bifurcate in "V" or "Y"), centrilobular nodules and opacities in "ground glass! are the most frequent patterns [11]. Except for a mosaic pattern of attenuation, which is highly suggestive of $O B$, it is often difficult to distinguish between severe asthma and bronchiolitis. Bronchoscopy and BAL are non-specific and only help to rule out other processes such as anatomic stenosis or endobronchial tumor, sarcoidosis, or hypersensitivity pneumonitis. Transbronchial biopsy offers conflicting results in post-transplantation OB. Definitive diagnosis usually requires a thoracoscopic or open lung biopsy. The findings are basically: infiltration of $\mathrm{T}$ lymphocytes around the small airways, bronchiolar smooth muscle hypertrophy, and bronchiectasis with mucus stasis, distortion, fibrosis, and total scarring of the bronchioles [16].

\section{Bronchiolitis and asthma}

Severe early-onset bronchiolitis is associated with an increased risk of asthma, especially after rhinovirus or RSV bronchiolitis, and an increased risk of asthma may persist into early adulthood [61,62]. An undefined aspect is up to which point early bronchiolitis in infancy damages normal lung development and predisposes to subsequent bronchospasm or even where certain infants have a preexisting aberration of immune response or airway function that predisposes them to severe bronchiolitis and recurrent bronchospasm [63]. Some work suggests the possibility that premorbid lung function may be abnormal among infants who have bronchiolitis in the first year of life [64]. A genetic predisposition to severe early bronchiolitis in life and the subsequent development of asthma is suggested by reports of associations between polymorphism in genes involved in the innate immune response and allergic responses, surfactant proteins and inflammatory cytokines [65]. From another perspective, Stein et al, presented recent evidence suggesting that the difference in the incidence of asthma between Old Order Amish versus the genetically related Hutterites may be due to variations in lifestyle that generates differences in the environmental microbiome (specifically domestic dust) [66]. Recent data reveal that the intestine-lung axis, particularly fecal microbiotic, may be a preventive factor against the development of viral respiratory tract infection [67]. It is conceivable that the asthma associated with viral respiratory tract disease could be 
prevented by alteration of the lung-intestine microbiotic. In the study by Ege et al., the protective effect against asthma in children exposed to a farm environment could be due to the influence of microbiotic on helper T cells type 1 and 2 [68]. All this indicates that there is a complex interaction between genetic and environmental factors in the development of asthma.

\section{Differential diagnosis}

In adults, asthma differs from bronchiolitis due to the presence of an obstruction to reversible airflow in spirometry. However, severe asthma may be associated with an irreversible limitation of airflow. A reduction in DLCO is uncommon in asthma, but common in bronchiolitis. The perfusion mosaic is very rare in asthma, but it is found in at least $50 \%$ of patients with bronchiolitis obliterans. Some patients with severe asthma have bronchiolitis obliterans with hypereosinophilic syndrome. These patients have poor response to inhaled steroids, peripheral eosinophilia (> 1000 cells / microL) and more than $25 \%$ of eosinophils in BAL. In HRCT, there are more changes in bronchiolitis than in asthma, and lung biopsy shows prominent infiltration of bronchiolar wall with eosinophils. Some authors classify this entity as hypereosinophilic bronchiolitis obliterans [69]. Sarcoidosis may have a similar presentation in terms of cough and dyspnea, and occasionally airway sarcoid is associated with airflow limitation. More frequently, sarcoidosis is associated with a restrictive pattern and decreased DLCO and unusually lung function may be normal. Lung biopsy will show well-formed non-caseous granulomas that make the diagnosis of sarcoidosis more likely.

Bronchocentric granulomatosis predominantly affects the bronchi but peribronchiolar inflammation may be present. The presence of fungal hyphae strongly supports the diagnosis.

Diffuse idiopathic pulmonary neuroendocrine cell hyperplasia (DIPNECH) is a neuroendocrine proliferation associated with a carcinoid tumor in which neuroendocrine cells are confined to the bronchial and bronchiolar epithelium. It is seen predominantly in women with cough and dyspnea, airflow limitation in spirometry and multiple small nodules $(4-10 \mathrm{~mm})$ in HRCT [70,71]. In one series, $44 \%$ of patients with DIPNECH had constrictive bronchiolitis [70]. Serum levels of chromogranin A may be elevated. Diagnosis requires lung transbronchial or surgical biopsy. The pulmonary neuroendocrine cells (PNE-C) are specialized epithelial cells, located through the respiratory tract from the trachea to terminal airways, and synthesize, store and release various amines and peptides. Among them, serotonin, calcitonin, chromogranin A (CgA) and gastrin-releasing peptide (GRP) [72]. DIPNECH is a form of preinvasive lesion that is located within the spectrum of neuroendocrine cell neoplasms and is associated with OB [73].

\section{Conclusions}

1) Bronchiolitis is a better-known event in the pediatric population than in the adult population.

2) In the adult population in many cases represents a pathophysiological response to various types of injury, monomorphic and nonspecific and only in some cases a well-established nosological entity.

3) In most patient's tissue is required to make the diagnosis and classification.

4) Even with histology, an adequate clinical, functional, radiological and histological correlation is required, since the findings may be common to several etiologies.

5) Treatment depends on the underlying cause.

6) More primary and clinical research is required to better delineate groups, pathophysiology, and to define diagnostic and prognostic markers.

7) This information will be basic to establishing prospective treatment protocols.

\section{Acknowledgement}

This work was carried out in collaboration between both authors. Authors AA and IA contributed equally in the planning, data collection, data analysis, writing and critical review. Both authors read and approved the final manuscript.

\section{References}

1. Montesi SB, Nance JW, Harris RS, Mark EJ (2016) CASE RECORDS of the MASSACHUSETTS GENERAL HOSPITAL. Case 17-2016. A 60-Year-Old Woman with Increasing Dyspnea. N Engl J Med 374: 2269-2279.[Crossref]

2. Barker AF, Bergeron A, Rom WN, Hertz MI (2014) Obliterative bronchiolitis. N Engl J Med 370: 1820-1828.[Crossref]

3. Center for Disease Control and Prevention (CDC) (2013)Obliterative bronchiolitis in worker in a coffee-processing facility- Texas. 2008-2012. MMWR Morb Mortal Wkly Rep 62: 305-307.[Crossref]

4. Niewoehner DE, Kleinerman J, Rice DB (1974) Pathologic changes in the peripheral airways of young cigarette smokers. $N$ Engl J Med 291: 755-758.[Crossref]

5. Tse HN, Raiteri L, Wong KY, Yee KS, Ng LY, et al. (2013) High-dose N-acetylcysteine in stable COPD: the 1-year, double-blind, randomized, placebo-controlled HIACE study. Chest 144: 106-118.[Crossref]

6. Goldman MD, Saadeh C, Ross D (2005) Clinical applications of forced oscillation to assess peripheral airway function. Respir Physiol Neurobiol 148: 179-194.[Crossref]

7. Papiris SA, Maniati M, Constantopoulos SH, Roussos C, Moutsopoulos HM, et al (1999) Lung involvement in primary Sjögren's syndrome is mainly related to the small airway disease. Ann Rheum Dis 58: 61-64.[Crossref]

8. Chia J, Chia A, Wang D, El-Habbal R, Sinokowitz D (2016) Chronic enterovirus D68 bronchiolitis causing severe respiratory insufficiency. Op J Respir Dis 6: 47-51.

9. Homma H, Yamanaka A, Tanimoto S, Tamura M, Chijimatsu Y, et al. (1983) Diffuse panbronchiolitis. A disease of the transitional zone of the lung. Chest 83: 63-69. [Crossref]

10. Tashtoush B, Okafor NC, Ramirez JF, Smolley L (2015) Follicular Bronchiolitis: A Literature Review. J ClinDiagn Res 9: OE01-OE05.[Crossref]

11. Devakonda A, Raoof S, Sung A, Travis WD, Naidich D (2010) Bronchiolar disorders: a clinical-radiological diagnostic algorithm. Chest 137: 938-951.[Crossref]

12. Hall CB, Weinberg GA, Iwane MK, Blumkin AK, Edwards KM, et al. (2009) The burden of respiratory syncytial virus infection in young children. $N$ Engl J Med 360 : 588-598.[Crossref]

13. Hasegawa K, Tsugawa Y, Brown DF, Mansbach JM, Camargo CA Jr (2013) Trends in bronchiolitis hospitalizations in the United States, 2000-2009. Pediatrics 132: 28-36. [Crossref]

14. Nair H, Nokes DJ, Gessner BD, Dherani M, Madhi SA, et al. (2010) Global burden of acute lower respiratory infections due to respiratory syncytial virus in young children: a systematic review and meta-analysis. Lancet 375: 1545-1555. [Crossref]

15. Haynes AK, Managan AP, Iwane MK, Sturm-Ramírez K, Homaira N, et al. (2013) Respiratory syncytial virus circulation in seven countries with Global Disease Detection regionals centers. J Infect Dis 3: S246-S254. [Crossref]

16. King TE Jr (2011) Bronchiolitis. In: Interstitial Lung Disease, (5th Edn) Schwartz MI King TE Jr (Eds).People's Medical Publishing House, Shelton, CT, USA p. 1003.

17. Falsey AR, Walsh EE (2000) Respiratory syncytial virus infection in adults ClinMicrobiol Rev 13: 371-384.[Crossref]

18. Cha SI, Shin KM, Kim M, Yoon WK, Lee SY, et al. (2009) Mycoplasma pneumoniae 
bronchiolitis in adults: clinical-radiologic features and clinical course. Scand J Infect Dis 41: 515-519.

19. Lauhkonen E, Koponen P, Vuononvirta J, Teräsjärvi J, et al. (2016) Gene Polymorphism of Toll-Like Receptors and Lung Function at Five to Seven Years of Age after Infant Bronchiolitis. PLoS One 11: e0146526.[Crossref]

20. Visscher DW, Myers JL (2006) Bronchiolitis: the pathologist's perspective. Proc Am Thorac Soc 3: 41-47.[Crossref]

21. Pipavath SJ, Lynch DA, Cool C, Brown KK, Newell JD (2005) Radiologic and pathologic features of bronchiolitis. AJR Am J Roentgenol 185: 354-363.[Crossref]

22. Howling SJ, Hansell DM, Wells AU, Nicholson AG, Flint JD, et al. (1999) Follicular bronchiolitis: thin-section CT and histologic findings. Radiology 212: 637-642. [Crossref]

23. Shipe R, Lawrence J, Green J, Enfield K (2013) HIV-associated follicular bronchiolitis. Am J Respir Crit Care Med 188: 510-511.[Crossref]

24. Randall TD (2010) Bronchus-associated lymphoid tissue (BALT) structure and function. AdvImmunol 107: 187-241.[Crossref]

25. Müller NL (2001) Advances in imaging. Eur Respir J 18: 867-871.[Crossref]

26. Escrig AC, Humaran BA, Sapia S, Ramírez JML (2013) Follicular bronquiolitis associated with common variable immunodeficiency.Arch Bronconeumol 49: 166-168.

27. Couture C, Colby TV (2003) Histopathology of bronchiolar disorders. Semin Respir Crit Care Med 24: 489-498.[Crossref]

28. Aubry MC (2014) Pulmonary Pathology: LC22-1 Non-neoplastic pulmonary lymphoid proliferations. Pathology 46: S36-37.

29. Chase NM, Verbsky JW, Hintermeyer MK, Waukau JK, Tomita-Mitchell A, et al. (2013) Use of combination chemotherapy for treatment of granulomatous and lymphoid interstitial lung disease (GLILD) in patients with common variable immunodeficiency (CVID). J ClinImmunol 33: 30-39. [Crossref]

30. Ryu JH (2006) Classification and approach to bronchiolar diseases. Curr Opin Pulm Med 12: 145-151.[Crossref]

31. Aerni MR, Vassallo R, Ryu JH (2005) Successful treatment of follicular bronchiolitis with macrolides. Chest 128: 4 .

32. Bates CA, Ellison MC, Lynch DA, Cool CD, Brown KK, et al. (2004) Granulomatouslymphocytic lung disease shortens survival in common variable immunodeficiency. $J$ Allergy Clin Immunol 114: 415-421. [Crossref]

33. Alvarado A, Arce I (2015) Molecular biology of chronic obstructive pulmonary disease from the bases to the therapeutic decision: a review. Br J Med Medic Res 10: 1-14.

34. Kuranishi LT, Leslie KO, Ferreira RG, Colleta EAN, Storrer KM, et al. (2015) Airwaycentered interstitial fibrosis: etiology, clinical findings, and prognosis. Respir Res 16 55. [Crossref]

35. Yousem SA, Dacic S (2002) Idiopathic bronchiolocentric interstitial pneumonia. Mod Pathol15: 1148-1153.[Crossref]

36. Fukuoka J, Franks TJ, Colby TV, Flaherty KR, Galvin JR, et al. (2005) Peribronchiolar metaplasia: a common histologic lesion in diffuse lung disease and a rare cause of interstitial lung disease: clinicopathologic features in 15 cases. Am J Sur Pathol 29: 948-954. [Crossref]

37. Barnes TW, Vassallo R, Tazelaar HD, Hartman TE, Ryu JH (2006) Diffuse bronchiolar disease due to chronic occult aspiration. Mayo Clin Proc 81: 172-176.[Crossref]

38. Hu X, Yi ES, Ryu JH (2015) Diffuse aspiration bronchiolitis: analysis of 20 consecutive patients. J Bras Pneumol 41: 161-166.[Crossref]

39. Keicho N, Hijikata M (2011) Genetic predisposition to diffuse panbronchiolitis. Respirology 16: 581-588.[Crossref]

40. Keicho N, Ohashi J, Tamiya G, Nakata K, Taguchi Y, et al. (2000) Fine localization of a major disease-susceptibility locus for diffuse panbronchiolitis. Am J Hum Genet 66: 501-507. [Crossref]

41. Anthony M, Singham S, Soans B, Tyler G (2009) Diffuse panbronchiolitis: not just an Asian disease: Australian case series and review of the literature. Biomed ImagInterv J 5: e19. [Crossref]

42. Kanoh S, Rubin BK (2010) Mechanisms of action and clinical application of macrolides as immunomodulatory medications. Clin Microbiol Rev 23: 590-615.[Crossref]

43. Rockey DC, Bell PD, Hill JA (2015) Fibrosis-A common pathway to organ injury and failure. $N$ Engl J Med 372: 1138-1149. [Crossref]
44. Hendrick DJ (2008) "Popcorn worker's lung" in Britain in a man making potato crisp flavoring. Thorax 63: 267-268.

45. Ryerson ChJ, Berkeley J, Carrieri-Kohlman VL, Pantilat SZ, Landefeld S, et al. (2011) Depression and functional status are strongly associated with dyspnea in interstitial lung disease. Chest 139:609-616. [Crossref]

46. King MS, Eisenberg R, Newman JH, Tolle JJ, Harrell FE Jr, et al. (2011) Constrictive bronchiolitis in soldiers returning from Iraq and Afghanistan. $N$ Engl J Med 365: 222230.[Crossref]

47. Williams KM, Chien JW, Gladwin MT, Pavletic SZ (2009) Bronchiolitis obliterans after allogeneic hematopoietic stem cell transplantation. JAMA 302: 306-314.[Crossref]

48. Dhillon GS, Zamora MR, Roos JE, Sheahan D, Sista RR, et al. (2010) Lung transplant airway hypoxia: a diathesis to fibrosis? Am J Respir Crit Care Med 182: 230-236. [Crossref]

49. Pettersson GB, Budev M (2010) The role of ischemia in postlung transplantation complications. Curr Opin Organ Transplant 15: 549-551.[Crossref]

50. Kirk R, Dipchand AI, Edwards LB, Kucheryavaya AY, Benden C, et al. (2012) The register of the International Society for Heart and Lung Transplantation: fifteenth pediatric lung and heart-lung transplantation report-2012. J Heart Lung Transplant 31: 1087-1095. [Crossref]

51. Christie JD, Edwards LB, Kucheryavaya AY, Benden C, Dipchand AI, et al. (2012) The Registry of the International Society for Heart and Lung Transplantation: 29th adult lung and heart-lung transplant report-2012. J Heart Lung Transplant 31: 1073-1086. [Crossref]

52. Treede H, Glanville AR, Klepetko W, Aboyoun Ch, Vettorazi E, et al. (2012) Tacrolimus and cyclosporine have differential effects on the risk of development of bronchiolitis obliterans syndrome: results of a prospective, randomized international trial in lung transplantation. J Heart Lung Transplant 31: 797-804. [Crossref]

53. Snell GI, Valentine VG, Vitulo P, Glanville AR, McGiffin DC, et al. (2006) Everolimus versus azathioprine in maintenance lung transplant recipients: an international, randomized, double-blind clinical trial. Am J Transplant 6: 169-177.[Crossref]

54. Vos R, Van Audenaerde BM, Verleden SE, Vleeschauwer D, Willems-Widyastutit A et al. (2011) A randomized controlled trial of azithromycin to prevent chronic rejection after lung transplantation. EurRespir J 37:164-172. [Crossref]

55. Vanaudenaerde BM, Meyts I, Vos R, Geudens N, De Weber W, et al. (2008) A dichotomy in bronchiolitis obliterans syndrome after lung transplantation revealed by azithromycin therapy. EurRespir J 32:832-843. [Crossref]

56. Federica M, Nadia S, Mónica M, Alessandro C, Tiberio O, et al. (2011) Clinical and immunological evaluation of 12-month azithromycin therapy on chronic lung allograft rejection. Clin Transplant 25: E381-389. [Crossref]

57. Vos R, Vanaudenaerde BM, Verleden SE, Ruttens D, Vaneylen A, et al. (2012) Antiinflammatory and immunomodulatory properties of azithromycin involved in treatment and prevention of chronic lung allograft rejection. Transplantation94:101-109. [Crossref]

58. Amagai M (2016) Modulating Immunity to Treat Autoimmune Disease. $N$ Engl J Med 375: 1487-1489.[Crossref]

59. Parambil JG, Yi ES, Ryu JH (2009) Obstructive bronchiolar disease identified by CT in the non-transplant population: analysis of 29 consecutive cases. Respirology 14: $443-$ 448. [Crossref]

60. Papiris SA, Malagari K, Manali ED, Kolilekas L, Triantafillidou Ch, et al. (2013) Bronchiolitis: adopting a unifying definition and comprehensive etiological classification. Expert Rev Respir Med7:289-306. [Crossref]

61. Chan JY, Stern DA, Guerra S, Wright AL, Morgan WJ, et al. (2015) Pneumonia in childhood and impaired lung function in adults: a longitudinal study. Pediatrics 135 607-616.[Crossref]

62. Calışkan M, Bochkov YA, Kreiner-Møller E, Bønnelykke K, Stein MM, et al. (2013) Rhinovirus wheezing illness and genetic risk of childhood-onset asthma. $N$ Engl J Med 368: 1398-1407.[Crossref]

63. Edwards MR, Bartlett NW, Hussell T, Openshaw P, Johnston SL (2012) The microbiology of asthma. Nat Rev Microbiol10: 459-471.[Crossref]

64. Drysdale SB, Wilson T, Alcazar M, Broughton S, Zuckerman M, et al. (2011) Lung function prior to viral lower respiratory tract infections in prematurely born infants. Thorax 66: 468-473.[Crossref]

65. Bucas KL, MianAI, Demmler-Harrison GJ (2013) Global gene expression profiling in infants with acute respiratory syncytial virus bronchiolitis demonstrates systemic 
activation of interferon signaling networks. Pediatr Infect Dis 32: e68-e76. [Crossref]

66. Stein MM, Hrusch CL, Gozdz J, Igartua C, Pivniouk V, et al. (2016) Innate Immunity and Asthma Risk in Amish and Hutterite Farm Children. N Engl J Med 375: 411-421. [Crossref]

67. Hasegawa K, Linnemann RW, Mansbach JM, Ajami NJ, Espinola JA, et al. (2016) The Fecal Microbiota Profile and Bronchiolitis in Infants. Pediatrics 138.[Crossref]

68. Ege MJ, Mayer M, Normand AC, Genuneit J, Cookson WO, et al. (2011) Exposure to environmental microorganisms and childhood asthma. $N$ Engl J Med 364: 701-709. [Crossref]

69. Meissner HC (2016) Viral bronchiolitis in children. NEngl J Med 374: 62-77. [Crossref]

70. Carr LL, Chung JH, Achcar RD, Lesic Z, Rho JY, et al (2015) The clinical course of diffuse idiopathic pulmonary neuroendocrine cell hyperplasia. Chest 147:415-422. [Crossref]

71. Nassar AA, Jaroszewski DE, Helmers RA, Colby TV, Patel BM, et al. (2011) Diffuse idiopathic pulmonary neuroendocrine cell hyperplasia: a systematic overview. Am J Respir Crit Care Med 184: 8-16.[Crossref]

72. Gorshtein A, Groos DJ, Barak D, Strenov Y, Refaeli Y, et al. (2012) Diffuse idiopathic pulmonary neuroendocrine cell hyperplasia and the associated lung neuroendocrine tumors: clinical experience with a rare entity. Cáncer 115: 612-619. [Crossref]

73. Trisolini R, Valentini I, Tinelli C, Farrari M, Guiducci GM, et al. (2016) DIPNECH association between histopathological and clinical presentation. Lung 194: 243-247. [Crossref]

Copyright: (C2017 Alvarado A. This is an open-access article distributed under the terms of the Creative Commons Attribution License, which permits unrestricted use, distribution, and reproduction in any medium, provided the original author and source are credited. 